\title{
Conventional mechanical ventilation in unilateral pulmonary contusion following blunt chest trauma
}

\author{
R. H. Gunawardana', M. Brabaharan ${ }^{2}$ and T. Athithan ${ }^{3}$
}

The Ceylon Journal of Medical Science 1996; 39: 75-77

\section{Summary}

Twelve patients with unilateral pulmonary contusion following blunt chest trauma received conventional mechanical ventilation for hypoxaemic respiratory failure. Nosocomial pneumonia and adult respiratory distress syndrome developed in all patients resulting in prolonged ventilator therapy. Conventional ventilatory support was not successful in reducing morbidity. The optimum pattern of mechanical ventilation in pulmonary contusion remains controversial. Split lung ventilation with selective separate tidal volumes and positive end expiratory pressure has shown encouraging results in some studies. Alternative treatment modalities are necessary to salvage oxygenation and reduce morbidity in these patients.

\section{Introduction}

Pulmonary contusion is a concussive loss of vessel integrity resulting in intraparenchymal and alveolar haemorrhage, decreased pulmonary compliance and increased shunt fraction (1). The lesion may be focal or may involve the whole lung. The treatment is selective and is based on the degree of respiratory impairment (2). Pulmonary contusion can be fatal because of respiratory insufficiency. The mortality from pulmonary contusion alone ranges from 14 to $40 \%$ (3). Mechanical ventilation (MV) is indicated in hypoxaemic patients to improve oxygenation. In flail chest, MV prevents the paradoxical movement of the chest wall.

The purpose of this study was to review our experience with conventional MV in pulmonary contusion following blunt chest trauma.

\section{Methods and Patient characteristics}

Twelve patients with a diagnosis of pulmonary contusion following blunt chest trauma admitted to the intensive care unit during the years 1985-1994 were studied retrospectively. All patients were admitted within $2-8 \mathrm{~h}$ of injury. The mechanisms of injury were, motor vehicle accident (3), fall from a height (3), assault (2), earthslips (2) and kicks by animals (2).

The mean age was $42(24-68)$ years. There were 10 males. The admission chest $x$-ray revealed unilateral widespread pulmonary contusion ( $40 \%$ right, $60 \%$ left). The remaining lung was normal in appearance. All had other thoracic injuries (Table 1). In 3 patients, there was associated haemorrhage into the tracheobronchial tree. They had cardiac contusions as detected by ECG and creatine phosphokinase isoenzymes. Echocardiography was not performed. The associated extrathoracic injuries are shown in Table 1.

Table 1. Associated injuries in 12 patients with pulmonary contusion

\begin{tabular}{|c|c|c|c|c|c|c|c|c|c|}
\hline \multicolumn{4}{|c|}{ Extrathoracic injuries } & \multicolumn{5}{|c|}{ Thoracic injuries } & \multirow[b]{2}{*}{$\begin{array}{l}\text { Number } \\
\text { of } \\
\text { patients }\end{array}$} \\
\hline $\begin{array}{l}\begin{array}{c}\text { Abdom- } \\
\text { inal }\end{array} \\
\mathrm{n}=3\end{array}$ & $\begin{array}{c}\text { Spinal } \\
n=3\end{array}$ & $\begin{array}{c}\text { Pelvic } \\
n=3\end{array}$ & $\begin{array}{c}\text { Lower } \\
\text { limb } \\
n=5 \\
\end{array}$ & $\begin{array}{c}\begin{array}{c}\text { Fracture } \\
\text { ribs }\end{array} \\
n=12\end{array}$ & $\begin{array}{c}\text { Flail } \\
\text { chest } \\
n=8\end{array}$ & $\begin{array}{c}\text { Haemo } \\
\text { /pneumo } \\
\text { thorax } \\
n=3 / 9\end{array}$ & $\begin{array}{c}\begin{array}{c}\text { Cardiac } \\
\text { contusion }\end{array} \\
n=3\end{array}$ & $\begin{array}{c}\begin{array}{c}\text { Sternal } \\
\text { fracture }\end{array} \\
n=1\end{array}$ & \\
\hline+ & + & + & + & + & + & + & - & - & 2 \\
\hline+ & + & - & - & + & + & + & - & - & $\mathbf{1}$ \\
\hline - & - & + & $+{ }^{\circ}$ & + & + & + & + & + & 1 \\
\hline- & - & - & + & + & + & + & + & - & 2 \\
\hline- & - & - & - & + & + & + & - & - & 2 \\
\hline - & - & - & - & + & - & + & - & - & 1 \\
\hline - & - & - & - & + & - & - & - & - & 3 \\
\hline
\end{tabular}

$\mathrm{n}=$ number of patients

1 Associate Professor, Department of Anaesthesiology, Faculty of Medicine, University of Peradeniya

2 Medical Officer, Intensive Care Unit, Teaching Hospital, Peradeniya.

3 Medical Officer, Intensive Care Unit, Teaching Hospital, Peradeniya. 
All patients were conscious, but tachypneic and hypoxaemic with a $\mathrm{PaO}_{2}$ of less than $80 \mathrm{~mm} \mathrm{Hg}$ on supplemental oxygen. Management included endotracheal intubation and MV. Intercostal tubes (prophylactic bilateral drainage in 5 patients) were left in situ whilst ventilation was in progress. All patients received neuromuscular blocking agents and intravenous morphine by continuous infusion. Fluid overloading was avoided. Corticosteroids were not administered. All received histamine 2 antagonists. No patient underwent thoracotomy. Six patients had surgery for extrathoracic injuries.

\section{Results}

Initially, all patients required MV with a tidal volume of $10 \mathrm{ml} / \mathrm{kg}$ and an inspired oxygen fraction $\left(\mathrm{FiO}_{2}\right)$ of 0.8 to maintain a $\mathrm{PaO}_{2}$ of $80 \mathrm{~mm} \mathrm{Hg}$. After 3-4 days, a $\mathrm{PaO}_{2}$ of $80 \mathrm{~mm}$. $\mathrm{Hg}$ could be maintained with a $\mathrm{FiO}_{2}$ of 0.6 . Volume cycled ventilators were used. The peak airway pressure exceeded $25 \mathrm{~cm} \mathrm{H}_{2} \mathrm{O}$ in all patients. Because of the risk of barotrauma, intercostal tubes were left in to ensure patient safety.

After 5-6 days of ventilator therapy, all patients developed gram negative nosocomial pneumonia. After a period of 7-9 days, the clinical picture and $x$-ray appearance were strongly suggestive of adult respiratory distress syndrome (ARDS) in all patients, although the diagnosis was difficult due to the overlapping pulmonary contusion and infection. They had refractory hypoxaemia, markedly reduced lung compliance and diffuse bilateral infiltrates. They required a tidal volume of $15 \mathrm{ml} / \mathrm{kg}$, a positive end expiratory pressure (PEEP) of $5-10 \mathrm{~cm}$ water and a $\mathrm{FiO}_{2}$ of over 0.6 for 8-17 days to maintain a $\mathrm{PaO}_{2}$ of $80 \mathrm{~mm} \mathrm{Hg}$. Hypocapnia occurred frequently in all patients during MV.

The air leaks continued for 5-8 days (mean 6) in patients with pneumothorax. Complications were frequent. All patients developed pneumonia and ARDS. Three patients with multiple (intra-abdominal and lower limb) injuries developed septicaemia and multiorgan failure and required multiple therapeutic interventions (dialysis, liver failure regimen, inotropic therapy, central venous pressure monitoring).
The chest $x$-ray returned to normal after a mean duration of 18 (14-27) days. The mean duration of M.V was 18 (15-32) days, with a mean ICU stay of 21 (19-42) days. The duration of MV of those patients with associated extrathoracic injuries was essentially the same as among those with only thoracic injuries.

\section{Discussion}

In the present series, the supine chest $x$-ray on admission was diagnostic of pulmonary contusion, indicating the severity of lung injury: The resulting hypoxaemic respiratory failure was refractory to oxygen therapy, requiring $M V$. Pulmonary dysfunction due to pain from multiple rib fractures and flail segments may be avoided by providing adequate pain relief (4), but contusion of the whole lung necessitated MV.

PEEP will improve hypoxaemia but does not change the underlying lung contusion (1). High airway pressures with high $\mathrm{FiO}_{2}$ probably aggravated the lung injury and prolonged weaning. The damaged lung also was not allowed to rest, thereby, delaying natural healing. Controversy exists on the pattern of ventilation in patients with pulmonary contusion. In order to prevent lung damage due to barotrauma and to improve oxygenation, other strategies such as inverse ratio ventilation (5-8), high frequency ventilation (9), and ventilation in the prone position (10) have been attempted, with variable results. Pressure controlled inverse ratio ventilation reduces peak airway pressure and enhances alveolar recruitment. Split lung ventilation may improve oxygenation and promote speedy recovery by allowing independent selection of tidal volumes and PEEP (11).

Although early withdrawal of continuous ventilatory support is advisable to reduce the incidence of complications associated with conventional MV, the superimposed pulmonary complications prolonged the duration of ventilation in the present series. Prophylactic antibiotic therapy was not helpful. Histamine 2 blockade probably increased the incidence of pulmonary infection. The contused lung segment is susceptible to infection (12), therefore, early bronchoscopy and 
bronchoalveolar lavage (13) and selective bowel decontamination (14) are suggested to reduce the incidence of posttraumatic pneumonia. Thoracoscopy too may prevent pneumonia by evacuation of clotted haemothorax and early removal of chest tubes (15). Fluid restriction, diuretics and corticosteroids have not shown much benefit in pulmonary contusion (16). Stress modification may control the inflammatory response to injury (17).

In our experience, conventional MV is not the best form of therapy for unilateral pulmonary contusion. Probably, the technique of independent lung ventilation and selective PEEP may be successful in this situation.

\section{References}

1. Oppenheimer L. Craven KD, Forket L, Wood LDH. Pathophysiology of pulmonary contusion in dogs. Journal of Applied Physiology 1979; 47: 718-728.

2. Richardson JD, Adams L, Flint LM. Selective management of flail chest and pulmonary contusion. Annals of Surgery 1982; 196: 481-483.

3. Kirsh MM, Sloan H. Blunt chest trauma. Little, Brown and Company; 1977; p 19-26.

4. Luchette FA, Radafshar SM, Kaiser R, Flynn W, Hassett JM. Prospective evaluation of epidural versus intrapleural catheters for analgesia in chest wall trauma. Journal of Trauma. 1994; 36: 869-870.

5. Shackford SR, Virgilo RW. Peters RM. Selective use of ventilator therapy in flail chest injury. Journal of Thoracic and Cardiovascular Surgery 1981; 81: 194-201.

6. Tharat RS, Allen RP, Albertson TE. Pressure controlled inverse ratio ventilation in severe adult respiratory failure. Chest 1988; 94: 755-757.

7. Ravizza AF, Carugo D, Cerchiari EL. Inversed ratios and conventional ventilations; comparison of the respiratory effects. Anaesthesiology 1983; 59: A53.
8. Lain DC, DiBenedetto R, Morris SL. Pressure control inverse ratio ventilation as a method to reduce peak inspiratory pressure and provide adequate ventilation and oxygenation. Chest 1982; 95: 1081.

9. Barzilay E, Lev A, Ibrihim M, Lesmes C. Traumatic respiratory insufficiency: Comparison of conventional mechanical ventilation to high frequency positive pressure with low rate ventilation. Critical Care Medicine 1987; 15: 118-121.

10. Gattinoni L, Pelosi P, Valenza F, Mascheroni D. Patient positioning in acute respiratory failure. In: Tobin MJ, ed. Principles and practice of mechanical ventilation. New York: McGraw Hill, 1994, p1067-1076.

11. Stow PJ, Grant I. Asynchronous independent lung ventilation: Its use in the treatment of acute unilateral lung disease. Anaesthesia 1985; 40: 163-165.

12. Richardson JD, Woods D, Johnson WG, Trinkle JK. Lung bacterial clearance following pulmonary contusion. Surgery 1979; 86: 730-735.

13. Regel G, Seekamp A, Aebert H, Wegener G, Sturm JA. Bronchoscopy in severe blunt chest trauma. Surgery-Endoscopy 1990; 4: 31-35.

14. Ledingham IMCA, Alcock SR, Eastaway ATC, McDonald JC. Triple regimen of selective decontamination of the digestive tract, systemic cefotaxime and microbiological surveillance for prevention of acquired infection in intensive care. Lancet 1988; 1: 785-790.

15. Smith RS, Fry WR, Tsoi EK, Morabito DJ. Preliminary report on videothoracoscopy in the evaluation and treatment of thoracic injury. American Journal of Surgery 1993; 166: 690-693.

16. Clark GC, Schecter WP, Trunkey DD. Variables affecting outcome in blunt chest trauma; flail chest vs. pulmonary contusion. Journal of Trauma 1988; 28: 298-304.

17. Demling RH, Pomfret EA. Blunt chest trauma. New-Horizon 1991; 1: 402-21. 